\title{
Production of an extracellular toxic complex by various strains of Pseudomonas cepacia
}

\author{
D. C. STRAUS, MIRIAM K. LONON, D. E. WOODS $\dagger$ and C. W. GARNER*
}

Departments of Microbiology and *Biochemistry, Texas Tech University Health Sciences Center, Lubbock, Texas 79430, and †Department of Microbiology and Infectious Diseases, The University of Calgary Health Sciences Centre, Calgary, Canada T2N 4 N1

\begin{abstract}
Summary. Six isolates of Pseudomonas cepacia, representing various serotypes of the organism and possessing similar degrees of virulence in mice, were examined for their production of an extracellular toxic complex (ETC) in vitro. This compound is lethal for mice and produces extensive lung pathology in rats; it is composed of a surface carbohydrate antigen, lipopolysaccharide and protein. All six isolates produced the ETC. The LD50 values for the six ETC preparations ranged from $395 \mu \mathrm{g}$ for strain $61 \mathrm{~g}$ to $1750 \mu \mathrm{g}$ for strain 90ee. Only two of the six ETC preparations contained ketodeoxyoctonate detectable by the methods used, and these two were the most toxic. Rabbit antiserum to the ETC of a serotype D strain could significantly protect mice only against serotype D strains. Examination of the various phases of growth of $P$. cepacia showed that there was extracellular release of the ETC beginning in the early logarithmic phase and continuing through the late stationary phase. The presence of the ETC in the supernatant fluids was due to release of this material rather than to cell lysis. In addition, at least one strain of $P$. cepacia was shown to produce an alginic acid-like compound.
\end{abstract}

\section{Introduction}

The importance of Pseudomonas cepacia as an opportunist pathogen in hospitalised patients and other compromised individuals is becoming increasingly evident (Goldmann and Klinger, 1986). Data from cystic fibrosis (CF) centres across the USA demonstrate that CF patients are at especially high risk of colonisation and infection (Corey et al., 1984; Isles et al., 1984; Thomassen et al., 1985, 1986) and are currently the largest patient population infected with $P$. cepacia. This is particularly distressing because of the cases of bacteraemia and fulminant necrotising pneumonia reported in this population (Isles et al., 1984; Thomassen et al., 1985). Because of the organism's resistance to a wide range of antimicrobial compounds, treatment of $P$. cepacia infections in CF patients is particularly difficult (Goldmann and Klinger, 1986).

We have recently described the production of an extracellular toxic complex (ETC) that appeared to be responsible for the lethality and the extensive lung pathology produced by $P$. cepacia in animals (Straus et al., 1988). The ETC consisted of a surface

Received 10 Oct. 1988; revised version accepted 25 Jan. 1989. carbohydrate antigen (CSA), lipopolysaccharide (LPS) and protein. Saponification studies demonstrated that the toxicity of the ETC was most probably associated with the LPS. We also showed that this material enhanced the virulence of $P$. cepacia when co-injected into mice (Straus et al., 1988). Because the ETC from only one strain of $P$. cepacia was employed in the above study, we have examined additional strains for the production of this compound.

\section{Materials and methods}

\section{Bacteria, bacterial virulence and media}

The $P$. cepacia strains employed in these studies were K19-2 (serotype A), K30-6 (serotype A), Pc 61g (serotype D), $710 \mathrm{~m}$ (serotypes A, D, E), 90ee (serotypes A, B, C, D, E), Pc99bb (serotype B), 5530pk (serotype C), Pc 527i (serotype D) and K63-2 (serotype E). The serotyping and origin of these strains were described by McKevitt et al., 1987). The storage of the organisms and the media employed have been previously described (Anwar et al., 1983b); LD50 was determined as previously described (Straus et al., 1988) and calculated by the method of Reed and Muench (1938). 
Purification, quantitation and chemical characterisation of the ETC from various strains of P. cepacia

Purification and quantitation of the ETC were done as previously described (Straus et al., 1988). The purified ETC was assayed for protein, ketodeoxyoctonate (KDO) and hexose by methods previously described (Straus $e t$ al., 1988). LPS was determined by the Limulus amoebocyte lysate (LAL) assay (Sullivan et al., 1976). Uronic acid content was measured by the procedure of Blumenkrantz and Asboe-Hansen (1973), with glucuronic acid (sodium salt; Sigma Chemical Co., St Louis, MO, USA) as the standard. KDO assays on the ETC were also run after exposure of the ETC to sweet potato acid phosphatase ( 25 units; Sigma) as described by Uehara et al. (1974) to determine if there were phosphate esters at the 4th or 5 th carbon atoms of KDO.

\section{Determination of the rate of production of ETC and percent lysis of $P$. cepacia at various points in the growth curve}

Cultures of strain Pc 61g were grown in $1 \mathrm{~L}$ of Anwar's medium (Anwar et al., 1983b) for $72 \mathrm{~h}$. Samples $(200 \mathrm{ml})$ were removed at optical-density $\left(\mathrm{OD}_{540}\right)$ values of $0 \cdot 1$ (lag phase), $0 \cdot 3$ (early log phase), $0 \cdot 6$ (late log phase), $1 \cdot 0$ (early stationary phase), and $1 \cdot 3$ (late stationary phase). The samples were immediately chilled on ice, and centrifuged at $17700 \mathrm{~g}$ for $30 \mathrm{~min}$ at $4^{\circ} \mathrm{C}$. The supernates were dialysed with stirring at $4^{\circ} \mathrm{C}$ against $8 \mathrm{~L}$ of deionised water for 3 days (with daily changes of water), and lyophilised. Samples were suspended in $5 \mathrm{ml}$ of distilled water and assayed for ETC by radial immunodiffusion as previously described (Straus et al., 1988). To determine the percentage lysis of $P$. cepacia at various points in the growth curve, we used the procedure described by Straus (1987).

\section{LD50 determinations and animal protection studies}

The LD50 of each of the ETC preparations was determined as previously described (Straus et al., 1988) and the value was calculated by the method of Reed and Muench (1938). Antiserum to the purified ETC of strain Pc 61g was prepared in rabbits as previously described (Straus et al., 1988) and serum was then referred to as immune rabbit serum (IRS). The following protocol was used to determine if anti-Pc 6lg ETC antibody would protect experimental animals against homologous and heterologous strains of $P$. cepacia. Strains K 19-2 (serotype A), Pc 99bb (serotype B), 5530 pk (serotype C), Pc 527i (serotype D), K63-2 (serotype E) and Pc 61g (serotype D) were grown to the stationary phase $\left(\mathrm{OD}_{540}=1.0\right)$ in Anwar's defined media (Anwar et al., 1983b). For every $5 \mathrm{ml}$ of washed $P$. cepacia cells in a beaker, $1.0 \mathrm{ml}$ of IRS was added. The same amount of washed bacteria was added to a beaker containing $1.0 \mathrm{ml}$ of normal rabbit serum (NRS) which served as a control. The beakers were incubated with stirring for $1 \mathrm{~h}$ at room temperature (RT). Then approximately 10 LD50 of $P$. cepacia of each serotype (exposed to either IRS or NRS) was injected intraperitoneally (i.p.) into Swiss-Webster mice. Deaths were recorded in both groups for 5 days.

\section{Analysis of CSA for alginic-acid}

Purification and quantitation of the CSA of strain Pc $61 \mathrm{~g}$ was done as previously described (Straus et al., 1988). CSA was analysed for hexuronic acid by the gas chromatographic method of Vadas et al. (1981). The method was verified by the analysis of alginic acid (Sigma: Catalogue No. A-2033). Gas chromatography was performed on a Perkin Elmer gas chromatograph, Model 3300, equipped with a flame ionisation detector. Acetyl groups were determined as the ferric hydroxamate by the method of McComb and McCready (1957).

\section{Isolation and characterisation of LPS from $P$. cepacia strain $61 \mathrm{~g}$}

$P$. cepacia strain $61 \mathrm{~g}$ was grown for $24 \mathrm{~h}$ in Anwar's medium as previously described (Straus et al., 1988) and $10 \mathrm{~L}$ were centrifuged at $17700 \mathrm{~g}$ for $60 \mathrm{~min}$. The LPS was purified from this cell pellet by the procedure of Staub (1967) and further purified by ultracentrifugation (Chedid et al., 1963). Endotoxic activity of the LPS was measured by the LAL assay (Sullivan et al., 1976). The LD50 value of the purified LPS preparation was determined in the same manner as that employed to determine the toxicity of the ETC preparations. The purified LPS from strain Pc 61g was also examined for the presence of KDO as previously described (Straus $e t$ al., 1988).

\section{Results}

\section{Production of ETC by various strains of P. cepacia}

Table I shows the production and LD50 values in mice of ETC from six $P$. cepacia isolates. All six isolates produced ETC with LD50 values ranging from $395 \mu \mathrm{g}$ for strain Pc $61 \mathrm{~g}$ to $1750 \mu \mathrm{g}$ for strain Pc $99 \mathrm{bb}$. However, all were relatively avirulent when injected i.p. into mice; the LD50 values for the six strains ranged from $2 \cdot 18 \times 10^{8}$ cfu to $9 \cdot 56 \times$ $10^{8} \mathrm{cfu}$. Furthermore, there was a wide range of variation in ETC production by these strains. For example, we were able to obtain $70 \mathrm{mg}$ of purified ETC from $10 \mathrm{~L}$ of strain $710 \mathrm{~m}$, whereas we obtained only $3 \mathrm{mg}$ from $10 \mathrm{~L}$ of strain K30-6.

The compositions of the various ETC preparations are also shown in table I. One of the most toxic ETC (that from strain $710 \mathrm{~m}$ with an LD50 value of $440 \mu \mathrm{g}$ ) had the highest percentage of LPS $(41.8 \%)$. The least toxic ETC (that from strain Pc 
Table I. Production and LD50 values in mice of purified ETC from six isolates of $P$. cepacia

\begin{tabular}{|c|c|c|c|c|c|c|c|c|}
\hline \multirow[b]{2}{*}{ Isolate } & \multirow{2}{*}{$\begin{array}{l}\text { LDS0* }^{*} \\
\text { (cfu) }\end{array}$} & \multirow{2}{*}{$\begin{array}{l}\text { ETC produced } \\
(\mathrm{mg} / 10 \mathrm{~L}) \dagger\end{array}$} & \multirow{2}{*}{$\begin{array}{c}\text { Presence of } \\
\mathrm{KDO}_{+}^{+}\end{array}$} & \multirow{2}{*}{$\begin{array}{l}\text { ETC LD50 } \\
(\mu \mathrm{g})^{*}\end{array}$} & \multicolumn{4}{|c|}{ Percentage composition of ETC $\S$} \\
\hline & & & & & LPS & Hexose & Protein & Uronic acid \\
\hline K 19-2 & $2.41 \times 10^{8}$ & $27 \cdot 0$ & - & 1000 & $29 \cdot 1$ & $58 \cdot 2$ & $11 \cdot 6$ & 0.9 \\
\hline K $30-6$ & $4.85 \times 10^{8}$ & $3 \cdot 0$ & - & 1000 & $27 \cdot 7$ & $33 \cdot 3$ & $36 \cdot 3$ & $2 \cdot 2$ \\
\hline Pc 61g & $2.89 \times 10^{8}$ & $20 \cdot 5$ & + & 395 & $29 \cdot 7$ & 61.9 & 1.9 & $6 \cdot 3$ \\
\hline $710 \mathrm{~m}$ & $5.20 \times 10^{8}$ & $70 \cdot 0$ & + & 440 & $41 \cdot 8$ & $46 \cdot 8$ & $8 \cdot 3$ & $2 \cdot 9$ \\
\hline $90 \mathrm{ee}$ & $9.56 \times 10^{8}$ & $11 \cdot 2$ & - & 1500 & $27 \cdot 1$ & $29 \cdot 8$ & $38 \cdot 0$ & $4 \cdot 8$ \\
\hline Pc $99 b b$ & $2 \cdot 18 \times 10^{8}$ & 14.9 & - & 1750 & $22 \cdot 7$ & $49 \cdot 1$ & $23 \cdot 6$ & 4.0 \\
\hline
\end{tabular}

* Determined after i.p. injection by the method of Reed and Muench (1938).

$\uparrow$ Purified as previously described (Straus et al., 1988).

$\ddagger$ Determined by the method of Osborn (1963); the assay can detect the presence of $\geqslant 0.5 \mu \mathrm{g}$ of $\mathrm{KDO} / 200 \mu \mathrm{l}$.

$\S$ Chemical analyses were performed as described in Materials and methods.

$99 \mathrm{bb}$ with an LD50 value of $1750 \mu \mathrm{g}$ ) had the lowest percentage of LPS $(22.7 \%)$. It was also quite interesting to note that the two most toxic ETC preparations (those from strains $\mathrm{Pc} 61 \mathrm{~g}$ and $710 \mathrm{~m}$ ) possessed detectable levels of KDO whereas the other four ETC preparations, with LD50 values of $\geqslant 1000 \mu \mathrm{g}$, did not appear to possess KDO. Preincubation of the six ETC preparations with 25 units of sweet potato acid phosphatase had no effect on the amount of KDO found in each preparation.

\section{Production of an alginic acid-like material by strain} $P c 61 g$ and an examination of the toxicity of its LPS

To determine if strains of $P$. cepacia taken from cases of $C F$ produce alginic acid, the carbohydrate surface antigen (CSA; pool II from DEAE-Sephacel; Straus et al., 1988) was analysed for its composition by gas chromatography as well as for acetylation. It consisted of approximately $72 \pm 3 \%$ guluronic acid and $11 \pm 4 \%$ mannuronic acid. No other carbohydrates were present. The material was $1.75 \pm 0.04 \%$ acetylated.

The purified LPS from strain Pc $61 \mathrm{~g}$ was found to be toxic in mice and possessed an LD50 in mice (when injected i.p.) of $1000 \mu \mathrm{g}$. This purified LPS preparation also possessed KDO, because it gave a pink colour with maximal absorption at $549 \mathrm{~nm}$ in the assay described by Osborn (1963).

\section{Ability of antibodies to ETC to passively protect experimental animals against homologous and heterologous $P$. cepacia challenge}

Approximately $10^{9} \mathrm{cfu}$ of at least one of the various serotypes of $P$. cepacia were incubated with IRS and NRS to determine if antibody to the ETC of one strain could protect experimental animals against homologous or heterologous challenge, or both. As can be seen in table II, rabbit antiserum to purified ETC from strain Pc $61 \mathrm{~g}$ significantly protected experimental animals only against serotype D organisms. IRS also appeared to offer some protection against strain $\mathrm{K} 63-2$, which is a serotype E strain. However, strain K63-2 appeared to be less virulent than the other strains tested, and the difference in mortality was not statistically significant. Antiserum to the ETC of strain Pc $61 \mathrm{~g}$ did

Table II. Ability of rabbit antibodies to ETC to protect passively against homologous and heterologous $P$. cepacia challenge

\begin{tabular}{llcc}
\hline $\begin{array}{c}\text { Source } \\
\text { of } \\
\text { serum }\end{array}$ & $\begin{array}{c}\text { Bacterial } \\
\text { challenge } \\
\text { strain* }\end{array}$ & Serotype & $\begin{array}{c}\text { Number of mice dead } / \\
\text { number of mice } \\
\text { challenged }(\%)\end{array}$ \\
\hline IRS & K19-2 & A & $5 / 5(100)$ \\
NRS & K19-2 & A & $5 / 5(100)$ \\
IRS & $99 \mathrm{bb}$ & B & $5 / 5(100)$ \\
NRS & $99 \mathrm{bb}$ & B & $5 / 5(100)$ \\
IRS & 5530 pk & C & $5 / 5(100)$ \\
NRS & 5530 pk & C & $5 / 5(100)$ \\
IRS & $61 \mathrm{~g}$ & D & $1 / 10(10) \dagger$ \\
NRS & $61 \mathrm{~g}$ & D & $10 / 10(100)$ \\
IRS & $527 \mathrm{i}$ & D & $4 / 10(40) \dagger$ \\
NRS & $527 \mathrm{i}$ & $\mathrm{D}$ & $10 / 10(100)$ \\
IRS & K63-2 & E & $6 / 16(37 \cdot 5)$ \\
NRS & K63-2 & E & $11 / 15(73 \cdot 3)$ \\
& & &
\end{tabular}

IRS=immune serum from rabbits immunised with purified ETC from strain Pc $61 \mathrm{~g}$ (serotype D) as described in the Materials and methods. NRS $=$ Normal rabbit serum.

* Dose c. $1 \times 10^{9} \mathrm{cfu}(10$ LD50).

† Significantly different from control by Fisher's Exact Test $(\mathrm{p}<$ $0.005)$. 
Table III. Production of ETC by strain Pc 61g during different phases of growth in Anwar's medium

\begin{tabular}{|c|c|c|c|c|c|c|}
\hline $\begin{array}{l}\text { Growth } \\
\text { phase }\end{array}$ & $\begin{array}{l}\text { Total cells/ } \\
200 \mathrm{ml}\end{array}$ & $\begin{array}{l}\text { Total ETC }(\mathrm{mg}) / \\
\text { 200-ml supernate }\end{array}$ & $\begin{array}{c}\text { ETC } \\
\text { produced/ } \\
\text { cell (ng) }\end{array}$ & $\begin{array}{c}\text { Total } \\
\text { supernate } \\
\text { DNA }(\mu \mathrm{g})\end{array}$ & $\begin{array}{c}\text { Total DNA } \\
\text { (supernate } \\
\text { plus pellet) } \\
(\mu \mathrm{g})\end{array}$ & $\begin{array}{l}\text { Percentage cell } \\
\text { lysis (total } \\
\text { supernate DNA/ } \\
\text { total DNA) }\end{array}$ \\
\hline Lag & $7.5 \times 10^{6}$ & ND & 0 & ND & $<10$ & 0 \\
\hline Early log & $1.14 \times 10^{8}$ & $3 \cdot 0$ & $26 \cdot 3$ & ND & 200 & 0 \\
\hline Late $\log$ & $6.92 \times 10^{8}$ & $3 \cdot 5$ & 5.06 & ND & 925 & 0 \\
\hline Early stationary & $9.51 \times 10^{8}$ & $8 \cdot 0$ & $8 \cdot 42$ & ND & 980 & 0 \\
\hline Late stationary & $1.09 \times 10^{9}$ & $10 \cdot 0$ & $9 \cdot 17$ & 37.5 & 1237 & $3 \cdot 0$ \\
\hline
\end{tabular}

$\mathrm{ND}=$ Not detected

not protect the mice against challenge with the other serotypes.

\section{Production of ETC at various points in the growth curve of strain Pc $61 \mathrm{~g}$}

Table III shows the production of ETC by strain Pc 61g during different phases of the growth curve. This table shows that, beginning in early log and continuing to late stationary phase, there is a continuous release of ETC. A determination of the total DNA found in the supernate allowed for an examination of the relationship between cell lysis and the extracellular release of the ETC. The only detectable cell lysis $(3.0 \%)$ occurred in the late stationary phase.

\section{Discussion}

We have recently described the production of an ETC by a strain of $P$. cepacia (Pc 61g) which appeared to be responsible for the lethality and the extensive lung necrosis associated with pneumonia produced by this organism in an animal model (Straus et al., 1988). In this report, we have shown that a further five strains of $P$. cepacia also produce ETC (table I). The amount of ETC produced ranged from $3 \mathrm{mg} / 10$-L culture of strain K30-6 to $70 \mathrm{mg} / 10-\mathrm{L}$ culture of strain $710 \mathrm{~m}$. The significance of this finding is unclear because the LD50 values for all the $P$. cepacia strains we examined, after i.p. injection, were $>2 \cdot 1 \times 10^{8}$ cfu for out-bred white mice. This is in agreement with the work of Jonsson (1970) who reported that the $P$. cepacia isolates he examined were not pathogenic for mice or guineapigs except in "extremely large doses".

The toxicity (LD50 values) of the ETC preparations also varied widely (from $395 \mu \mathrm{g}$ for strain $\mathrm{Pc}$ $61 \mathrm{~g}$ to $1750 \mu \mathrm{g}$ for strain Pc 99bb). The most toxic ETC preparations, those from strains $\mathrm{Pc} 61 \mathrm{~g}$ and
$710 \mathrm{~m}$, contained the highest concentrations of LPS. When the LPS from one strain of $P$. cepacia (Pc $61 \mathrm{~g}$ ) was isolated and purified, it was found to possess KDO and to be toxic in mice. This confirms that the LPS portion of the ETC confers toxicity on the complex. It should also be noted that the most toxic ETC preparations also possessed KDO, whereas the least toxic ETC preparations apparently did not. Previously, we have been able to detect extracellular KDO in approximately $20 \%$ of the $P$. cepacia strains that we examined (Straus et al., 1988). Manniello et al. (1979) were the first to report that there was no detectable KDO in biologically active LPS preparations extracted from the strains of $P$. cepacia, as determined by the procedure of Osborn (1963). This conclusion was supported by Anwar et al. (1983a) in their studies on the outer membrane of one strain of $P$. cepacia. In this study, we treated the ETC with sweet potato acid phosphatase (Uehara et al., 1974) before examination for KDO by the procedure described by Osborn (1963). This enzyme has been shown to hydrolyse phosphate esters of secondary alcohols, such as those found in the 4-phosphate and 5phosphate esters of KDO. Treatment of all ETC preparations with sweet potato acid phosphatase had no significant effect on the amount of KDO detected in each preparation, indicating that no phosphate esters of secondary alcohols were present. We have examined a further 25 strains and have found that approximately $25 \%$ of them produce a KDO-possessing ETC (Straus et al., unpublished observations) that is detectable by the methods we are currently employing. However, it should be pointed out that several authors have reported finding LPS lacking $\mathrm{KDO}$ in other bacteria, which were later shown by more stringent methods to contain KDO (Rietschel et al., 1988). We are now attempting to detect $\mathrm{KDO}$ in the strains that we consider to be KDO-lacking by 
more sophisticated technology such as gas chromatography.

Immunisation of rabbits with the ETC of strain $\mathrm{Pc} 61 \mathrm{~g}$ resulted in the production of antibodies that could protect $90 \%$ of experimental animals against 10 LD50 doses of the homologous strain (table II). Indeed, this antiserum could protect $60 \%$ of experimental animals against 10 LD50 doses of the heterologous $P$. cepacia strain 527i. Both of these strains, however, possess the D serotype, which may explain the protective capability of the serum. In developing the serotyping scheme for P. cepacia, McKevitt et al. (1987) showed that the LPS determined serotype specificity. Therefore, antibodies against the LPS-containing ETC of strain Pc $61 \mathrm{~g}$ would be expected to opsonise all serotype D strains, and possibly the serotype E strains, because serum to whole cells of serotype $\mathrm{D} P$. cepacia agglutinated serotype E organisms (McKevitt et al., 1987). The data in table II are fairly convincing that antibodies to the LPS of $P$. cepacia can offer protection against experimental challenge. Other studies have shown the protective effect of antibodies to LPS, e.g., in $P$. aeruginosa infections, the most important protective antibodies are directed against cell associated antigens of the organism (Young, 1972). These antibodies do not appear to inactivate any known virulence factor of the bacterium, but rather function as opsonic antibody to increase the efficiency of phagocytosis and resultant killing of the pathogen by professional phagocytes (Young and Armstrong, 1972). McKevitt et al. (1987) have shown cross-reactions between type A, which has smooth LPS phenotype, and type $B$ which has a rough phenotype. In that study, the serotype A strain agglutinated in antiserum prepared against both the serotype $A$ and serotype B strains. The serotype B strain agglutinated only with its homologous serum. The authors concluded from these data that the serotype B strain is a subtype of the serotype A strain, because immunoblotting of the purified LPS preparations of the two strains demonstrated that the antibodies were directed against different determinants. This suggests that the core region of $P$. cepacia LPS may be an important antigenic determinant.

The ETC of strain Pc 61g appears to be released in all phases of growth except the lag phase (table III). ETC is released as a natural product of cell growth and is not due to cell lysis. This is not surprising, because it has been shown that, as other gram-negative bacteria grow in vitro, they shed outer membrane LPS into liquid media (Mackowiak, 1984). These LPS molecules, most commonly found in association with phospholipids and bacterial outer membranes (Rothfield and PearlmanKothencz, 1969; Gankema et al., 1980), are thought to be released into the external environment by bacteria in fragments of outer membranes (Russell, 1976). We have previously shown that a similar LPS-containing complex is produced in vivo by at least one strain of P. cepacia (Straus et al., 1988).

At least one strain of $P$. cepacia $(\mathrm{Pc} 61 \mathrm{~g})$ produces an alginic acid-like compound, the CSA. Polysaccharides produced by mucoid strains of $P$. aeruginosa are heteropolymers composed of Dmannuronosyl and L-guluronosyl moieties and invariably contain acetyl groups (Carlson and Matthews, 1966; Linker and Jones, 1966; Evans and Linker, 1973). Evans and Linker (1973) compared the polysaccharides from mucoid strains of $P$. aeruginosa isolated from $C F$ patients and patients with urinary tract infections for algal alginic acid. They showed that the ratio of $L$ guluronosyl to D-mannuronosyl moieties and the acetyl content of the polymers differed, depending upon the strain of bacterium examined. In their study, D-mannuronosyl residues were the most abundant and, in certain instances, represented as much as $91 \%$ of the polysaccharide. The percentage acetylation of strains in their study ranged from 13.4 to $4.1 \%$. Algal alginate, also composed entirely of D-mannuronosyl and L-guluronosyl residues (Linker and Jones, 1966; Evans and Linker, 1973) was found to be unacetylated. In this study, we have shown that the alginic acid-like compound produced by $P$. cepacia strain $61 \mathrm{~g}$ is approximately $72 \%$ guluronic acid and is $1.75 \%$ acetylated. We showed in a previous report (Straus et al., 1988) that active immunisation of mice with this material (the CSA) could protect them against at least one heterologous strain of $P$. cepacia. It is difficult, at this time, to relate this finding to the protection studies with rabbit antibody to the ETC of the same organism, because ETC and CSA certainly represent different compounds in view of their dissimilar elution patterns on DEAE-Sephacel (Straus et al., 1988). The significance of these findings is unclear.

We thank David J. Hentges for his critical review of this manuscript. This study was supported by a Biomedical Research grant from Texas Tech University Health Sciences Center and a grant from the Canadian Cystic Fibrosis Foundation to D.E.W. 


\section{REFERENCES}

Anwar H, Brown M R W, Cozens R M, Lambert P A $1983 a$ Isolation and characterization of the outer and cytoplasmic membranes of Pseudomanas cepacia. Journal of General Microbiology 129: 499-507.

Anwar H, Brown M R W, Lambert P A $1983 b$ Effect of nutrient depletion on sensitivity of Pseudomonas cepacia to phagocytosis and serum bactericidal activity at different temperatures. Journal of General Microbiology 129: 2031-2027.

Blumenkrantz N. Asboe-Hansen G 1973 New method for quantitative determination of uronic acids. Analytical Biochemistry 54: 484-489.

Carlson D M, Matthews L W 1966 Polyuronic acids produced by Pseudomonas aeruginosa. Biochemistry 5: 2817-2822.

Chedid L, Skarnes R C, Parant M 1963 Characterization of a $\mathrm{Cr}^{51}$-labeled endotoxin and its identification in plasma and urine after parenteral administration. Journal of Experimental Medicine 117: 561-571.

Corey M, Allison L, Prober C, Levison H 1984 Sputum bacteriology in patients with cystic fibrosis in a Toronto hospital during 1970-1981. Journal of Infectious Diseases 149: 283.

Evans L R, Linker A 1973 Production and characterization of the slime polysaccharide of Pseudomonas aeruginosa. Journal of Bacteriology 116: 915-924.

Gankema H, Wensink J, Guinee P A M, Jansen W H, Witholt B 1980 Some characteristics of the outer membrane material released by growing enterotoxigenic Escherichia coli. Infection and Immunity 29: 704-713.

Goldmann D A, Klinger J D 1986 Pseudomonas cepacia: biology, mechanisms of virulence and epidemiology. Journal of Pediatrics 108: 806-812.

Isles A et al. 1984 Pseudomonas cepacia infection in cystic fibrosis: an emerging problem. Journal of Pediatrics 104: 206-210.

Jonsson V 1970 Proposal of a new species Pseudomonas kingii. International Journal of Systematic Bacteriology 20:255-257.

Linker A, Jones R S 1966 A new polysaccharide resembling alginic acid isolated from Pseudomonads. Journal of Biological Chemistry 241 : 3845-3851.

Mackowiak P A 1984 Relationship between growth temperature and shedding of lipopolysaccharides by gram-negative bacilli. European Journal of Clinical Microbiology 3: 406410.

Manniello J M, Heymann H, Adair F W 1979 Isolation of atypical lipopolysaccharides from purified cell walls of Pseudomonas cepacia. Journal of General Microbiology 112: 397-400.

McComb E A, McCready R M 1957 Determination of acetyl in pectin and in acetylated carbohydrate polymers. Hydroxamic acid reaction. Analytical Chemistry 29: 819-821.

McKevitt A I, Retzer M D, Woods D E 1987 Development and use of a serotyping scheme for Pseudomonas cepacia. Serodiagnosis and Immunotherapy 1 : 177-184.
Osborn M J 1963 Studies on the gram-negative cell wall. I. Evidence for the role of 2-keto-3-deoxyoctonate in the lipopolysaccharide of Salmonella typhimurium. Proceedings of the National Academy of Science of the USA 50: 499-506.

Reed L J, Muench H 1938 A simple method of estimating fiftypercent endpoints. American Journal of Hygiene 27: 493497.

Rietschel E T et al. 1988 Bacterial endotoxins: properties and structure of biologically active domains. In: Schrinner E et al. (eds) Surface structures of microorganisms and their interactions with the mammalian host. $\mathrm{VCH}$, New York, pp 1-38.

Rothfield L, Pearlman-Kothencz M 1969 Synthesis and assembly of bacterial membrane components. A lipopolysaccharidephospholipid-protein complex excreted by living bacteria. Journal of Molecular Biology 44: 477-492.

Russell R R B 1976 Free endotoxin-a review. Microbios Letters 2: $125-135$.

Staub A M 1967 Preparation of antigens and antibodies. In: Williams C A, Chase M W (eds) Methods in immunology and immunochemistry, vol. I. Academic Press, New York, pp 28-34.

Straus D C 1987 Production of an extracellular toxic complex by various strains of Klebsiella pneumoniae. Infection and Immunity 55: 44-48.

Straus D C, Woods D E, Lonon M K, Garner C W 1988 The importance of extracellular antigens in Pseudomonas cepacia infections. Journal of Medical Microbiology 26: 269-280.

Sullivan J D, Valois F W, Watson S W 1976 Endotoxins: The Limulus amebocyte system. In: Bernheimer A W (ed) Mechanisms in bacterial toxinology. John Wiley and Sons, New York, p 217

Thomassen M J, Demko C A, Doershuk C F, Stern R C, Klinger J D 1986 Pseudomonas cepacia: decrease in colonization in patients with cystic fibrosis. American Review of Respiratory Diseases 134: 669-671.

Thomassen M J, Demko C A, Klinger J D, Stern R C 1985 Pseudomonas cepacia colonization among patients with cystic fibrosis. American Review of Respiratory Diseases 131 : 791-796.

Uehara K, Fujimoto S, Taniguchi K, Nakai K 1974 Studies on violet-colored acid phosphatase of sweet potato. II. Enzymatic properties and amino acid composition. Journal of Biochemistry 75 : 639-649.

Vadas L, Prihar H S, Pugashetti B K, Feingold D S 1981 A gas chromatographic method for the quantitative determination of hexuronic acids in alginic acid. Analytical Biochemistry 114: 294-298.

Young L S 1972 Human immunity to Pseudomonas aeruginosa II. Relationship between heat-stable opsonins and typespecific lipopolysaccharides. Journal of Infectious Diseases 126: $277-287$.

Young L S, Armstrong D 1972 Human immunity to Pseudomonas aeruginosa. I. In-vitro interaction of bacteria, polymorphonuclear leukocytes, and serum factors. Journal of Infectious Diseases 126: 257-276. 